\title{
Pyruvate dehydrogenase E1-alpha deficiency
}

INSERM

\section{Source}

INSERM. (1999). Orphanet: an online rare disease and orphan drug data base. Pyruvate dehydrogenase E1-alpha deficiency. ORPHA:79243

Pyruvate dehydrogenase E1-alpha deficiency is the most frequent form of pyruvate dehydrogenase deficiency (PDHD, see this term) characterized by variable lactic acidosis, impaired psychomotor development, hypotonia and neurological dysfunction. 